CLINICAL STUDY

\title{
The prevalence and characteristic features of cyclicity and variability in Cushing's disease
}

\author{
Krystallenia I Alexandraki ${ }^{1,2}$, Gregory A Kaltsas ${ }^{1,2}$, Andrea M Isidori ${ }^{1}$, Scott A Akker ${ }^{1}$, William M Drake ${ }^{1}$, \\ Shern L Chew ${ }^{1}$, John P Monson ${ }^{1}$, G Michael Besser ${ }^{1}$ and Ashley B Grossman ${ }^{1}$ \\ ${ }^{1}$ Department of Endocrinology, St Bartholomew's Hospital, London EC1A 7BE, UK and ${ }^{2}$ Division of Endocrinology, Department of Pathophysiology, \\ School of Medicine, Laiko General Hospital, National \& Kapodistrian University of Athens, Athens 115 27, Greece
}

(Correspondence should be addressed to A B Grossman; Email: a.b.grossman@qmul.ac.uk)

\begin{abstract}
Objective: Cyclical Cushing's syndrome may render the diagnosis and management of Cushing's disease difficult. The aim of the present study was to investigate the prevalence of cyclicity and variability in patients with Cushing's disease, and to identify putative distinctive features.

Design: Retrospective case-note study.

Methods: We analysed the case records of 201 patients with Cushing's disease in a retrospective casenote study. Cyclicity was considered as the presence of at least one cycle, defined as a clinical and/or biochemical hypercortisolaemic peak followed by clinical and biochemical remission, followed by a new clinical and/or biochemical hypercortisolaemic peak. The fluctuations of mean serum cortisol levels, as assessed by a 5-point cortisol day curve, defined the variability.

Results: Thirty (14.9\%; 26 females) patients had evidence of cyclicity/variability. 'Cycling' patients were older but no difference in sex or paediatric distribution was revealed between 'cycling' and 'noncycling' patients. The median number of cycles was two for each patient, and 4 years was the median intercyclic period. A trend to lower cure rate post-neurosurgery and lower adenoma identification was observed in 'cycling' compared with 'non-cycling' patients. In multivariate analysis, older patients, longer follow-up, female sex and no histological identification of the adenoma were associated with an increased risk of cyclic disease.

Conclusions: This large population study reveals that cyclicity/variability is not an infrequent phenomenon in patients with Cushing's disease, with a minimum prevalence of $15 \%$. Physicians should be alert since it can lead to frequent problems in diagnosis and management, and no specific features can be used as markers.
\end{abstract}

European Journal of Endocrinology 160 1011-1018

\section{Introduction}

Cushing's syndrome (CS) due to excess endogenous cortisol production has been occasionally described as cyclical (1) but with variable other descriptions such as periodic hormonogenesis (2), unpredictable hypersecretion of cortisol (3), fluctuating steroid excretion $(4,5)$ or intermittent CS (6). It has been more frequently described in pituitary-dependent CS, Cushing's disease, having being characterized by periodic increases and decreases in cortisol levels, clinically and/or biochemically documented $(2,7,8)$. However, it has been considered to be an uncommon phenomenon, since only a few small series and case reports confirm its presence $(9,10)$. It is important to consider that acute investigation may be associated with episodes of lowered activity and delays in definitive diagnosis. Similarly, apparent 'cure' after surgical treatment may simply reflect a nadir in activity and be falsely reassuring. Furthermore, fluctuating disease activity may render medical control extremely difficult. Intermittent as well as sustained cortisol hypersecretion might be associated with considerable morbidity and mortality, necessitating effective definitive treatment $(11,12)$.

Although most experienced endocrine physicians recognize this phenomenon, it has proven difficult to define it robustly. Cyclicity has been commonly defined as the occurrence of three peaks and two troughs of hypercortisolaemia (9), but this cannot be readily applied to all patients since the intercyclic period may vary and may be so long as to defy a clear assessment.

Cyclicity has also been reported in patients with adrenal tumours (13) and ectopic ACTH syndrome (14), but it is most described in patients with Cushing's disease. Owing to the lack of any comprehensive data on the prevalence of the phenomenon, the aim of the present study was to investigate the presence of 'cyclicity' (defined as the presence of clinical and biochemical peaks and troughs) and of 'variability' (biochemical fluctuations of cortisol secretion) in a large 
cohort of patients with Cushing's disease. In addition, some characteristics of this discrete patient population have been investigated.

\section{Materials and methods}

We analysed retrospectively the data in 201 patients with Cushing's disease, consecutively admitted from 1946 through to 2007 to the Department of Endocrinology, St Bartholomew's Hospital London, with the authorization of our institutional case-note review committee (registration number 08/76). The diagnosis of Cushing's disease was based on the presence of typical symptoms and signs based on a fixed departmental protocol, along with detailed biochemical evaluation, including circadian rhythm studies, lowand high-dose dexamethasone suppression tests (LDDST, HDDST), the CRH stimulation test, and bilateral inferior petrosal sinus sampling (BIPSS) with CRH (a routine procedure in our Department from 1985). Confirmation of Cushing's disease was based on the histopathological diagnosis of a corticotroph tumour and/or clinical and biochemical remission following transsphenoidal surgery (TTS), and/or biochemical confirmation of ACTH-dependent CS with a central gradient on BIPSS (15).

For the present study, the following demographic data were extracted from the case records of each patient: gender, age at presentation, symptoms and signs of hypercortisolism, years of follow-up, diagnostic workup, therapeutic modalities, pituitary imaging studies and pathology results.

A cycle was defined as a clear-cut clinical and/or biochemical hypercortisolaemic peak followed by a clinical and biochemical remission and at least by a new clear-cut clinical and/or biochemical hypercortisolaemic state. Cyclicity was considered to be the presence of at least one cycle. The clinical peak was documented by the appearance and disappearance of specific cushingoid features, according to the detailed clinical records. This assessment was based on the registration of changes (improvement or exacerbation) observed using a clinical assessment system with the advantage of collecting information methodically from a single institution on the basis of a consistent protocol in which specific symptoms/signs were assigned as either present or absent. This to some extent eliminates individual variations of the interviewing physicians in data accrual $(16,17)$, but is similar to many lists extant in the literature (15). The biochemical peak, characterized by the biochemical confirmation of hypercortisolaemia as previously described (15), was assessed using the cortisol daycurve (CDC, involving measuring serum cortisol levels at five fixed times through a day) (18). This assessment was consistently performed in our department, and is based on a normal range established in a normal control group and supported by an isotopic dilution technique (18). Each cycle was then further characterized as clinical, biochemical, or both. When the hypercortisolaemic state was not present as a cycle but as fluctuations of mean serum cortisol levels, assessed by a 5-point CDC, it was defined as variability. Besides the presence of cortisol fluctuations, it was arbitrarily decided to confirm variability by the presence of doubling (mean level increase $>200 \%$ over basal values) or halving (mean level decrease $<50 \%$ from basal) of the serum cortisol during CDC performance, in the absence of therapy or without a change in therapy in order to minimize nonphysiological changes due to possible assay variability error $(9,19-21)$.

As an example of this calculation, we found one patient who first presented to her general practitioner with clinical CS which then remitted; 3.5 years later her clinical features recurred and she had increased urine free cortisol (UFC); 2 months later her UFC was normal and she suppressed on a LDDST. A further 2 months later her UFC was again increased and she was admitted for diagnostic work-up. She was administered mitotane and the dose remained stable with a CDC between 363 and 423; however, some 6 years from her previous hypercortisolaemic peak on a stable dose of mitotane for 4 years she presented with a CDC $700 \mathrm{nmol} / \mathrm{l}$ (Fig. 1).

A second patient was not cured by surgery and was treated medically while awaiting the delayed effects of radiotherapy; however, during this period she was difficult to control medically because of variation in her CDC, and after 6 years she finally had bilateral adrenalectomy. As shown in Fig. 2, a hypercortisolaemic peak was present in November 1996 and another in

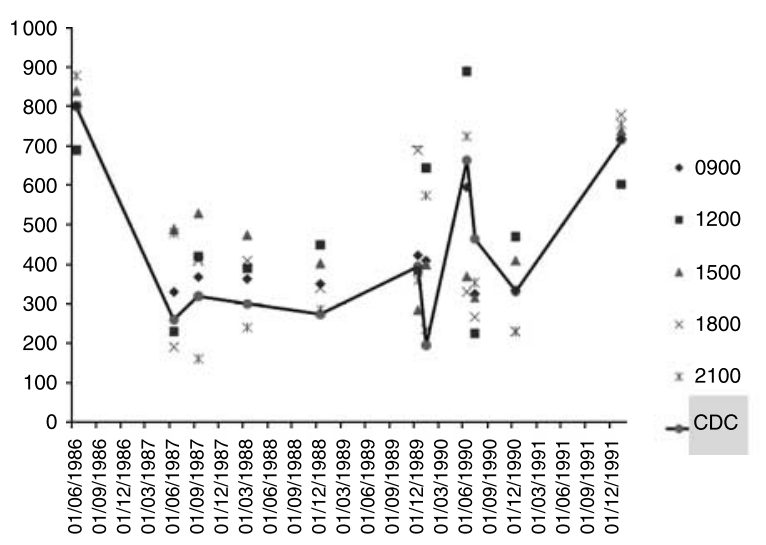

Figure 1 Cortisol 'day curve' (nmol/l) assessment of a patient under long-term stable medical treatment with varying levels of cortisol. CDC: blood samples were taken at 0900, 1200, 1500, 1800 and $2100 \mathrm{~h}$ from the patient, the serum cortisol measured, and the mean value calculated. Individual values and the mean level are shown in the graph. Previous data based on normal volunteers and an isotopic dilution technique demonstrated that in normal subjects the mean of these five values should lie between 150 and $300 \mathrm{nmol} / \mathrm{l}$. See text for references. 


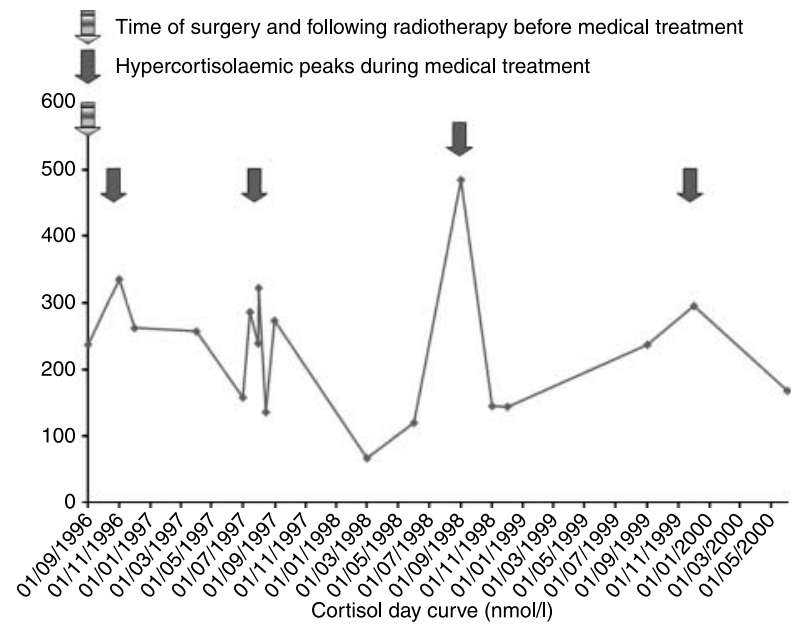

Figure 2 Cortisol 'day curve' (nmol/l) levels in a patient after the confirmation of the diagnosis and following medical treatment after surgical failure. The arrows indicate the time of surgery and following radiotherapy before medical treatment, and the hypercortisolaemic peaks that can be compared as the patient was on the same treatment at these four time points.

August 1997 on unchanged therapy. Two subsequent cycles on unchanged medication revealed peaks in September 1997, September 1998 and December 1999.

Finally, as an example of cyclicity before the admission for the confirmation of $\mathrm{CS}$, a patient presented with clinically florid CS to her general practitioner who remitted in 2 weeks; 2 years later another episode of clinically florid CS lasted 2 months. The third peak presented 27 months later when the patient was fully investigated and cured by surgery and radiotherapy.

Cyclicity/variability was recorded if present: i) prior to the first presentation of the investigation of CS and consequently before any therapeutic intervention, based on clinical ground or biochemical data provided by the previous medical history, or ii) after the confirmation of the diagnosis and following any form of acute or chronic therapeutic modality. The length of the cycle was determined as the duration from one apparent peak of clinical or biochemical CS activity until the following peak.

The case records of all patients were carefully evaluated according to departmental protocols. Cases with simple progression from a mild form to the overt disease, the on-going effects of chronic treatment such as radiotherapy or mitotane withdrawal, self-changing treatment doses or non-compliance with medication, significant alcohol consumption or significant dietinduced weight or incomplete data recording were excluding criteria from the definition of cyclicity or variability.

During the follow-up period, clinical parameters and cortisol secretion were assessed at least at 3-month intervals for clinical purposes, or more frequently, usually monthly, when required, using the mean cortisol levels through the day (CDC). Follow-up assessment was performed yearly after 3 years of confirmed remission. In order to perform a uniform and consistent data analysis, other hormonal data were not analysed since only the CDC was formally assessed in the whole population studied. While the possibility of ectopic CS was considered during follow-up in all the cases of Cushing's disease with negative histology, no case of ectopic disease was identified (15). No case of adrenal insufficiency was recorded during the periods of remission in any of the patients studied.

Post-operative cure was defined by biochemical and clinical remission of CS.

The paediatric population was considered to include any patient with Cushing's disease $<18$ years old.

\section{Statistical analysis}

Values are presented as mean value \pm s.E.M. Statistical significance in the results was accepted at a $P$ value $<0.05$. The normal distribution of continuous variables was assessed by applying the non-parametric Kolmogorov-Smirnov test. Comparisons between groups were made by an independent-sample $t$-test. The Mann-Whitney $U$ test was performed for variables which were not normally distributed. Correlations between categorical variables were estimated by the $\chi^{2}$ test or with Fisher's exact test when appropriate. Odds ratio and $95 \%$ confidence interval for binary outcomes in univariate and multiple logistic models were calculated and reported. Cyclic disease presence was the dependent variable. Analysis was performed using SPSS (version 11.01; SPSS Inc., Chicago, IL, USA) for Windows XP (Microsoft Corp).

\section{Results}

The whole group of the 201 patients (154 women, $76.6 \%$ ) initially presented at a mean age of $37.6 \pm 1.15$ (range: 7-95) years and were followed up for a mean period of 14.1 \pm 0.7 (range: from presentation-52) years; $8.5 \%(17 / 201)$ of the total group were $<18$ years old at presentation. Nine patients of the total cohort were studied only at presentation.

Evidence of cyclicity or variability was observed in 30 patients, of which 26 were female. These patients had a mean age of $42.3 \pm 2.0$ years at presentation and were followed up for a mean period 14.8 \pm 1.6 (range: from presentation-30) years. The 'cycling' did not differ from the 'non-cycling' group in sex ratio or years of followup, but did differ in age at presentation. Cyclicity/variability was present in $16.88 \%(26 / 154)$ of females and in $8.52 \%(4 / 47)$ of males; $1 / 17(5.88 \%)$ of the paediatric patients showed cyclicity (Tables 1 and 2 ).

In $27(90 \%)$ of these patients there was recorded at least one cycle (median: 2 ; range: $1-4$ ) and variability 
in $12(40 \%)$. In a total of 54 recorded cycles, eight were only clinical, 39 clinical and biochemical and seven biochemical alone. The mean cycle length was $3.8 \pm 0.6$ years. Only in one patient was a stable intra-cyclic period every 1.5 years in two cycles observed. Evidence of cyclic disease before diagnosis was present in 12 patients, before diagnosis and during follow-up in nine patients, and during follow-up in nine patients. Consequently, in the whole 'cycling' subgroup, evidence of cyclic disease before diagnosis was present in 21 (70\%) patients, and in the follow-up in 18 (60\%; Table 1).

In the 19 patients with cyclicity/variability submitted to TTS, six were cured (post-operative serum cortisol at $0900 \mathrm{~h}<50 \mathrm{nmol} / \mathrm{l}$ ), while four had remission with recurrence. Of the cured patients only two had postoperative serum cortisol levels $<50 \mathrm{nmol} / \mathrm{l}$ in the immediate post-operative period, while four patients had higher levels which fell gradually over 3-7 days. In one 'not-cured' patient, radiotherapy was performed immediately after the documentation of the detectable post-operative serum cortisol levels, confounding further interpretation. A trend for lower cure rates and a lower rate of pituitary adenoma identification in histology was found in the patients showing cyclicity. The presence of a macroadenoma (two in 'cycling' and 28 in the 'noncycling' patients) did not differ between the groups. Eight of the 'cyclic' patients required bilateral adrenalectomy compared with 47 'non-cycling' patients; the median follow-up period in those subgroups was 23 years (range: 9-30 years) and 20.5 years (range: 0-52 years) respectively; Nelson's syndrome was diagnosed in two (of eight) 'cyclic' patients and 19 (of 47) 'non-cyclic'.

Table 1 Summary of the characteristic features of cyclicity and variability in the population studied.

\begin{tabular}{|c|c|}
\hline Parameters studied & Cyclic population \\
\hline Overall, prevalence of cyclicity or variability & $30 / 201(14.9 \%)$ \\
\hline Prevalence of cyclicity & $27 / 201(13.43 \%)$ \\
\hline Prevalence of variability & $12 / 201(5.97 \%)$ \\
\hline Female population & $26 / 30(86.67 \%)$ \\
\hline Male population & $4 / 30(13.33 \%)$ \\
\hline $\begin{array}{l}\text { Paediatric population (17 patients, } \\
<18 \text { years) }(\%)\end{array}$ & $1 / 17(5.88 \%)$ \\
\hline Median number of cycles (range) & $2(1-4)$ \\
\hline Length of cycles (mean \pm S.E.M., years) & $3.8 \pm 0.6(0.2-26)$ \\
\hline \multicolumn{2}{|l|}{ Type of 54 cycles } \\
\hline Clinical cycles & $8(14.8 \%)$ \\
\hline Clinico-biochemical cycles & $39(72.2 \%)$ \\
\hline Biochemical cycles & $7(13.0 \%)$ \\
\hline \multicolumn{2}{|l|}{ Time of diagnosis } \\
\hline Before diagnosis & $12(40 \%)$ \\
\hline After treatment & $9(30 \%)$ \\
\hline Before diagnosis + after treatment & $9(30 \%)$ \\
\hline Prevalence of cyclicity + variability & $9(30 \%)$ \\
\hline Prevalence of cyclicity only & $18(60 \%)$ \\
\hline Prevalence of variability only & $3(10 \%)$ \\
\hline
\end{tabular}

Table 2 Summary of the distinctive and common characteristics found in patients with cyclic and non-cyclic disease.

\begin{tabular}{|c|c|c|c|}
\hline $\begin{array}{l}\text { Parameters } \\
\text { studied }\end{array}$ & $\begin{array}{l}\text { Cyclic } \\
(n=30)\end{array}$ & $\begin{array}{l}\text { Non-cyclic } \\
(n=171)\end{array}$ & $\boldsymbol{P}$ \\
\hline $\begin{array}{l}\text { Mean age (range) } \\
\text { (years) }\end{array}$ & $42.3 \pm 2.0(17-72)$ & $36.8 \pm 1.1(7-95)$ & 0.02 \\
\hline $\begin{array}{l}\text { Mean follow up } \\
\text { (range) (years) }\end{array}$ & $14.8 \pm 1.6(0-30)$ & $14.0 \pm 0.8(0-52)$ & 0.68 \\
\hline Female (\%) & $26 / 30(86.67 \%)$ & $128 / 171(74.85 \%)$ & 0.24 \\
\hline $\begin{array}{l}\text { Paediatric } \\
\text { population (\%) }\end{array}$ & $1 / 30(3.33 \%)$ & $16 / 171(9.36 \%)$ & 0.48 \\
\hline $\begin{array}{l}\text { Macroadenoma } \\
\text { presence }\end{array}$ & $2(6.67 \%)$ & $67(16.37 \%)$ & 0.53 \\
\hline $\begin{array}{l}\text { Bilateral } \\
\quad \text { adrenalectomy }\end{array}$ & $8(26.67 \%)$ & 47 (27.49\%) & 0.90 \\
\hline $\begin{array}{l}\text { Nelson's } \\
\text { syndrome }\end{array}$ & $2 / 8(25 \%)$ & $19 / 47$ (40.4\%) & 0.70 \\
\hline $\begin{array}{l}\text { Block and } \\
\text { replacement } \\
\text { treatment }\end{array}$ & $2(6.67 \%)$ & $(-)$ & \\
\hline Neurosurgery & $n=19$ & $n=127$ & \\
\hline Cured & $6(31.58 \%)$ & $67(52.76 \%)$ & 0.09 \\
\hline Recurrence & $4(21.05 \%)$ & $12(9.45 \%)$ & \\
\hline Not cured & $9(47.37 \%)$ & $48(37.79 \%)$ & \\
\hline Pathology & $n=19$ & $n=127$ & \\
\hline $\begin{array}{l}\text { Adenoma } \\
\text { identification }\end{array}$ & 9/19 (47.37\%) & $83 / 127$ (65.35\%) & 0.09 \\
\hline Imaging & $n=30$ & $n=156$ & \\
\hline $\begin{array}{l}\text { Suggestive/ } \\
\text { diagnostic } \\
\text { findings }\end{array}$ & $19(63.3 \%)$ & 109 (69.87\%) & 0.52 \\
\hline
\end{tabular}

$P<0.05$ is taken as statistically significant, results at this level are indicated in bold.

Two 'cyclic' patients were controlled with 'block-andreplacement' modalities but no patients in the 'noncycling' group required this treatment. Interestingly, imaging studies suggested or confirmed the presence of an adenoma (including macroadenomas) at the first presentation in 19 'cycling' patients and 109 'non-cycling' (Table 2).

In four $(13.3 \%)$ patients we noted a clear paradoxical rise in serum cortisol level following either the LDDST or HDDST.

Variability in the signs and symptoms of hypercortisolism are reported in Table 3. Only gastrointestinal symptoms and galactorrhoea in the females appeared to differ between 'cyclic' and 'non-cyclic' patients, but after allowance for multiple comparisons this was no longer statistically significant.

Older patients were found more likely to have a cyclic disease in univariate analysis. In multivariate analysis, however, after adjusting for other covariates, older patients, longer follow-up and female sex were associated with an increased risk of cyclic disease, whereas 'adenoma identification' was associated with a significantly lower risk for cyclic disease (Table 4).

No difference was found between the patients with only cyclicity, with cyclicity and variability, or only variability, in terms of age, years of follow-up, cure rates after neurosurgery, imaging or pathologic findings. 
Table 3 Symptoms and signs of hypercortisolism in the two populations.

\begin{tabular}{|c|c|c|c|}
\hline Parameters studied & $\begin{array}{l}\text { Cyclic } \\
(n=30)\end{array}$ & $\begin{array}{l}\text { Non-cyclic } \\
(n=171)\end{array}$ & $\boldsymbol{P}$ \\
\hline Cushingoid appearance & $22(73.3 \%)$ & $139(81.3 \%)$ & 0.22 \\
\hline Easy bruising/ecchimosis & $21(70 \%)$ & $86(50.1 \%)$ & 0.07 \\
\hline Weight gain & $19(63.3 \%)$ & $111(64.9 \%)$ & 0.84 \\
\hline Hypertension & $18(60 \%)$ & $118(69.0 \%)$ & 0.29 \\
\hline $\begin{array}{l}\text { Proximal myopathy/proximal } \\
\text { muscles wasting }\end{array}$ & $17(56.7 \%)$ & $83(48.5 \%)$ & 0.55 \\
\hline Depression & $14(46.7 \%)$ & $50(29.2 \%)$ & 0.09 \\
\hline Obesity/central adiposity & $13(43.3 \%)$ & $101(59.1 \%)$ & 0.11 \\
\hline Thin skin & $12(40 \%)$ & $56(32.7 \%)$ & 0.54 \\
\hline Change in exercise ability & $12(40 \%)$ & $64(37.4 \%)$ & 1.00 \\
\hline Headaches/migraines & $11(36.7 \%)$ & $55(32.2 \%)$ & 0.68 \\
\hline Oedema & $11(36.7 \%)$ & $51(29.8 \%)$ & 0.53 \\
\hline Gastrointestinal symptoms & $11(36.7 \%)$ & $30(17.5 \%)$ & 0.03 \\
\hline $\begin{array}{l}\text { Buffalo hump/cervival or } \\
\text { intrascapular fat pad }\end{array}$ & $10(33.3 \%)$ & $62(36.3 \%)$ & 0.84 \\
\hline Striae & $9(30 \%)$ & $71(41.5 \%)$ & 0.23 \\
\hline $\begin{array}{l}\text { Skeletomuscular/joints } \\
\text { aches }\end{array}$ & $9(30 \%)$ & $52(30.4 \%)$ & 1.00 \\
\hline Disuric symptoms & $9(30 \%)$ & $36(21.5 \%)$ & 0.35 \\
\hline Infection & $9(30 \%)$ & $41(24 \%)$ & 0.50 \\
\hline Skin pigmentation & $9(30 \%)$ & $31(18.1 \%)$ & 0.15 \\
\hline $\begin{array}{l}\text { Cardiovascular } \\
\text { disease/symptoms }\end{array}$ & $9(30 \%)$ & $37(21.6 \%)$ & 0.35 \\
\hline Fatigue & $8(26.7 \%)$ & $32(18.7 \%)$ & 0.33 \\
\hline Acne & 7 (23.3\%) & $49(28.7 \%)$ & 0.66 \\
\hline Other psychiatric disorders & $7(23.3 \%)$ & $35(20.5 \%)$ & 0.81 \\
\hline $\begin{array}{l}\text { Dizziness/drops } \\
\text { attacks/lethargy }\end{array}$ & $7(23.3 \%)$ & $29(17 \%)$ & 0.44 \\
\hline Visual disturbances & $6(20 \%)$ & $38(22.2 \%)$ & 1.00 \\
\hline $\begin{array}{l}\text { Abnormal carbohydrate } \\
\text { metabolism }\end{array}$ & $6(20 \%)$ & $29(17 \%)$ & 0.80 \\
\hline Emotional lability & $5(16.7 \%)$ & $21(12.3 \%)$ & 0.56 \\
\hline Skin disorders & $5(16.7 \%)$ & $34(19.9 \%)$ & 0.81 \\
\hline Sleep disorders & $4(13.3 \%)$ & $17(9.9 \%)$ & 0.53 \\
\hline Flushing/red face & $4(13.3 \%)$ & $27(15.8 \%)$ & 1.00 \\
\hline Sexual dysfunction & $4(13.3 \%)$ & $35(20.5 \%)$ & 0.46 \\
\hline Osteoporosis/fracture & $4(13.3 \%)$ & $20(11.7 \%)$ & 0.77 \\
\hline Neurological symptoms & $4(13.3 \%)$ & $23(13.5 \%)$ & 1.00 \\
\hline Anxiety/panic & $3(10 \%)$ & $18(10.5 \%)$ & 1.00 \\
\hline Increased sweating & $3(10 \%)$ & $14(8.2 \%)$ & 0.73 \\
\hline Hair thin/dry & $3(10 \%)$ & $12(7 \%)$ & 0.71 \\
\hline Poor healing & $2(6.7 \%)$ & $4(2.3 \%)$ & 0.23 \\
\hline Fundus abnormalities & $2(6.7 \%)$ & $10(5.8 \%)$ & 1.00 \\
\hline Loss of weight & $1(3.33 \%)$ & $5(2.9 \%)$ & 1.00 \\
\hline Renal calculi & $1(3.3 \%)$ & $7(4.1 \%)$ & 1.00 \\
\hline Thirst/polydipsia & $1(3.3 \%)$ & $10(5.8 \%)$ & 1.00 \\
\hline Thyroid disorders & $1(3.3 \%)$ & $3(1.8 \%)$ & 0.49 \\
\hline $\begin{array}{l}\text { Mental alterations } \\
\text { (memory/concentration } \\
\text { disturbances, slowness) }\end{array}$ & 0 & $13(7.6 \%)$ & 0.22 \\
\hline $\begin{array}{l}\text { Poor growth/short stature } \\
\text { Female population }\end{array}$ & $\stackrel{0}{n=26}$ & $\begin{array}{l}9(5.3 \%) \\
n=128\end{array}$ & 0.47 \\
\hline Hirsutism & $23(88.5 \%)$ & $103(80.5 \%)$ & 0.57 \\
\hline Virilization & $6(23.1 \%)$ & $35(27.3 \%)$ & 1.00 \\
\hline Menstrual irregularity & $12(46.2 \%)$ & $63(49.2 \%)$ & 0.83 \\
\hline Galactorrhoea & $5(19.2 \%)$ & $6(4.7 \%)$ & 0.02 \\
\hline
\end{tabular}

$P<0.05$ is taken as statistically significant before adjustment for multiple comparisons, results at this level are indicated in bold.

However, the presence of cyclicity was more prevalent before diagnosis as opposed to being seen in the followup period $(P=0.02)$; variability was equally present before as well as after treatment.

\section{Discussion}

In this study, it has been shown that cyclical or variable CS as defined by specific diagnostic criteria had a prevalence of $\sim 15 \%$ in a large series of patients with Cushing's disease, of whom $70 \%$ showed cyclicity or variability before the diagnosis was made and any therapy initiated. It is interesting that very similar percentages of $17 \%$ ( $42 \%$ with the first evidence postoperatively) (22) and 18\% (50\% with the first evidence post-operatively) (23) were reported in small series of patients submitted to neurosurgical treatment, although a somewhat higher figure was suggested in an early series from Northern Ireland (24).

If cyclicity is a feature of the patient's presentation, confirmation of the diagnosis can be difficult, particularly if the patient is evaluated during the period of 'cycling out' (24). The diagnostic work-up may be particularly difficult in this 'trough' period, as at that time the routine diagnostic tests may all be apparently normal. Such variability may also interfere with effective treatment before definitive cure; in the first place, post-operative 'cure' may be mistakenly ascribed to effective surgery when the disease is simply in an inactive phase. Furthermore, the use of medical therapy may be complicated by variability in the control of the disease which may lead to alternating periods of overand under-treatment, increasing the necessity for more definitive therapy such as bilateral adrenalectomy. However, the finding of an approximately similar frequency of cyclicity being present before and after treatment does not indicate any particular period in the natural history to be more important, even if cycles were more commonly identified before treatment. We noted that most often two cycles, three peaks, were seen in each patient with an intercyclic period of $\sim 4$ years. Interestingly, a stable intra-subject periodicity of cycles was not observed, other than in a single patient. This would imply that regular cyclicity with ' $12 \mathrm{~h}$ to 85 days' periodicity, as has been previously suggested, can clearly occur, but seems much less frequent than more irregular and unpredictable fluctuations. $(2,10,25)$. Isolated clinical and biochemical cycles showed similar frequencies: clinical along with biochemical cycles were the most commonly identified, implying no additive information from laboratory data for the investigation of cyclicity. This finding suggests the importance of the signs and symptoms as being a harbinger of a new hypercortisolaemic peak. On the other hand, laboratory data are clearly important in confirming such variability, and this might be aided by the use of home-testing with salivary cortisol (26); this has previously been shown to be particularly useful in establishing the definitive diagnosis and follow-up of 'cyclic' patients with rapid fluctuations in hormonal secretion (3).

The population demonstrating cyclicity and variability do not seem to show any special defining characteristics, although the group as a whole had a 
Table 4 The association of the parameters studied in terms of the presence of cyclic disease.

\begin{tabular}{|c|c|c|c|c|c|c|}
\hline \multirow[b]{2}{*}{ Factors studied } & \multicolumn{3}{|c|}{ Results from univariate analysis } & \multicolumn{3}{|c|}{ Results from multiple analysis } \\
\hline & OR & $95 \% \mathrm{Cl}$ & $P$ value & OR & $95 \% \mathrm{Cl}$ & $P$ value \\
\hline Age at presentation & 1.03 & $1.00-1.05$ & 0.05 & 1.04 & $1.00-1.09$ & 0.03 \\
\hline Years of follow up & 1.01 & $0.97-1.05$ & 0.72 & 1.08 & $1.00-1.16$ & 0.05 \\
\hline Sex & 2.10 & $0.69-6.37$ & 0.19 & 6.18 & $1.12-34.27$ & 0.04 \\
\hline Adenoma identification on pathologic specimen & 0.43 & $0.17-1.17$ & 0.09 & 0.30 & $1.00-0.96$ & 0.04 \\
\hline Radiologic evidence of pituitary abnormality & 0.75 & $0.33-1.69$ & 0.48 & 0.70 & $0.18-2.79$ & 0.61 \\
\hline Bilateral adrenalectomy performed & 0.94 & $0.39-2.25$ & 0.88 & 0.52 & $1.00-2.75$ & 0.44 \\
\hline Macroadenoma presence & 0.53 & $0.11-2.43$ & 0.41 & 0.62 & $0.10-3.72$ & 0.60 \\
\hline
\end{tabular}

$P<0.05$ is taken as statistically significant, results at this level are indicated in bold.

slight but significantly higher mean age; this may reflect the impact of such variability in delaying diagnosis. There was no obvious difference between the adult and paediatric groups, but the number of patients in the latter was small.

The cure rates in patients with cyclicity/variability showed a trend to be lower compared with the "noncycling' population with Cushing's disease, but the numbers are again small. Low surgical cure rates have been previously reported in cyclic Cushing's disease, and are in contrast with the commonly referred $80-90 \%$ cure rate of Cushing's disease $(27,28)$. However, the apparent low cure rates in the total population may simply reflect the fact that patients were recruited over a prolonged period of time, with low cure rates being seen in the early years that this form of surgery was used. The same trend towards a difference between cyclic and noncyclic disease was observed in terms of the presence of histological confirmation of an adenoma, which was less commonly seen in patients with cyclical disease. These findings may be prognostically useful in advising such patients, and may even be a determinant of the type of pituitary operation attempted, i.e. total hypophysectomy as opposed to microadenomectomy. Furthermore, the percentage of patients requiring bilateral adrenalectomy did not differ from the general population, although 'block-and-replacement' to control adrenal function appeared to be used in patients with cyclic disease. It has been previously suggested that pituitary-directed medical treatment, such as bromocriptine (29) or sodium valproate (30), might be particularly valuable in these patients, but the evidence for this is slim and in general these agents are not notably effective (31).

Imaging studies do not seem to be useful in identifying cyclic disease since the proportion of patients with abnormal imaging was also broadly concordant between the groups. While in general the signs and symptoms also did not seem to differ between the two populations, there appeared to be a difference in gastrointestinal symptoms and in galactorrhoea in females, but it is unclear if those are truly of clinical significance. We did note the previously described (25) paradoxical responses to dynamic tests observed in a small percentage of this population, further emphasizing the limitations of dynamic testing in these patients $(6,7,9,32,33)$ : this response has mainly been reported in patients with ACTHindependent primary pigmented nodular adrenal dysplasia (34). However, while clearly clinicians need to be aware of this pitfall in diagnosis, most centres emphasize the utility of the BIPSS in patients with ACTH-dependent CS, along with the vital necessity of assessing the serum cortisol on the day of testing to confirm that the disease is active at the time of the procedure (18). As noted above, salivary cortisol assessment may prove a useful option, offering a more rapid home-assessment of fluctuations in cortisol secretion $(3,35)$.

Notably, female sex, longer follow-up period and the older age of patients at presentation seem to increase the risk of identifying 'cyclic' disease. However, it is difficult to conclude that these features can be considered specific, although the need for life-long follow-up is clear. In addition, histological confirmation of an adenoma was found to be less associated with cyclicity.

Interestingly, no difference was observed between cyclicity and variability in any of the parameters studied, other than the time of diagnosis, implying that there is no reason to analyse these parameters of cortisol fluctuations differently. Such 'unpredictable hypersecretion', which may or not be periodic, may represent a common patho-physiologic process. The molecular basis for this significant variability in hormonal release has been little studied in molecular terms (36). Several hypotheses have been suggested to explain the phenomenon, including episodic haemorrhage, the synchronous growth and death of tumour cells $(9,10)$ or fluctuations in adrenal-pituitary axis feedback (14). It seems unlikely that there is abnormal hypothalamic control as such regulation should be absent in the presence of an autonomous tumour $(9,28,37-40)$. One might speculate that the innate circadian rhythmicity of the tumorous corticotrophs is disturbed, which may account for the changes in ACTH output, although the long time course is difficult to reconcile with this theory. 
There are clearly a number of limitations to this study. Firstly, it is retrospective and relied totally on patient recall of the clinical situation before diagnosis, and the reports by the physicians in the medical case records. Hence, the data presented are descriptive. However, we believe that they are clinically useful as they seek to quantify, as far as possible in a retrospective survey (since no prospective studies have been published), such oscillations in clinical and biochemical activity. In addition, the cyclicity or variability of the patients might have been under-diagnosed since we adopted very strict specific criteria. Nevertheless, all patients were followed up in a single unit with unified protocols, such that there was a relatively uniform assessment. Consequently, it can be emphasized that the calculated prevalence reflects the minimum prevalence in this idiosyncratic group of patients. In addition, most patients with a diagnosis of Cushing's disease are immediately treated and surgically cured, such that residual cyclicity and variability will no longer be seen. However, in spite of these limitations this is the first large-scale survey of this phenomenon, and its relatively high frequency suggests that there is a necessity for large prospective studies where more biochemical and clinical data can be properly evaluated. While the CDC is not in common use, we have found that it provides a good approximation to biochemical activity (18). The alternative would have been to have used $24 \mathrm{~h}$ urinary cortisol excretion, but these assays are less reliably established and subject to errors in collection (19). For a large retrospective survey such day curves might presently represent the best estimate of biochemical activity we have available considering the unknown validity of the other diagnostic tests in 'cyclic' disease $(32,33)$.

In summary, we report a prevalence of $\sim 15 \%$ of cyclicity and variability in patients with Cushing's disease on clinical and/or biochemical criteria, with no particular specific characteristic defining this population which could help to differentiate them from patients lacking cyclicity. Such phenomena may lead to problems in confirmation of the diagnosis and/or result in dilemmas in deciding on initial treatment, particularly when surgery fails requiring bilateral adrenalectomy or medical treatment. We suggest that this is a minimum prevalence, and marked fluctuations in cortisol secretion might be a more common characteristic of Cushing's disease than previously considered. The absence of commonly accepted criteria for the definition of cyclicity implies the necessity for prospective studies and for the setting of common guidelines. Physicians should be alert to the presence of cyclical CS since its presence influences the confirmation of diagnosis as well as therapeutic decisions in to order to optimize the effective management of the disease, and to effectively control the potential longterm sequelae.

\section{Declaration of interest}

There is no conflict of interest that could be perceived as prejudicing the impartiality of the research reported.

\section{Funding}

This research did not receive any specific grant from any funding agency in the public, commercial or not-for-profit sector.

\section{References}

1 Oates TW, McCourt JP, Friedman WA, Agee OF, Rhoton AL \& Thomas WC Jr. Cushing's disease with cyclic hormonogenesis and diabetes insipidus. Neurosurgery 19795 598-603.

2 Bailey RE. Periodic hormonogenesis-a new phenomenon. Periodicity in function of a hormone-producing tumor in man. Journal of Clinical Endocrinology and Metabolism 197132 317-327.

3 Hermus AR, Pieters GF, Borm GF, Verhofstad AA, Smals AG, Benraad TJ \& Kloppenborg PW. Unpredictable hypersecretion of cortisol in Cushing's disease: detection by daily salivary cortisol measurements. Acta Endocrinologica 1993128 428-432.

4 Zondek H, Zondek GW \& Leszynsky HE. Fluctuability of steroid excretion. Acta Endocrinologica 195726 91-95.

5 Bassoe HH, Emberland R \& Stoa KF. Fluctuating steroid excretion in Cushing's syndrome. Acta Endocrinologica 195828 163-168.

6 Brooks RV, Jeffcoate SL, London DR, Prunty FT \& Smith PM. Intermittent Cushing's syndrome with anomalous response to dexamethasone. Journal of Endocrinology 196636 53-61.

7 Atkinson AB, McCance DR, Kennedy L \& Sheridan B. Cyclical Cushing's syndrome first diagnosed after pituitary surgery: a trap for the unwary. Clinical Endocrinology 199236 297-299.

8 Vagnucci AH \& Evans E. Cushing's disease with intermittent hypercortisolism. American Journal of Medicine 198680 83-88.

9 Meinardi JR, Wolffenbuttel BH \& Dullaart RP. Cyclic Cushing's syndrome: a clinical challenge. European Journal of Endocrinology $2007157245-254$.

10 Mantero F, Scaroni CM \& Albiger NM. Cyclic Cushing's syndrome: an overview. Pituitary 20047 203-207.

11 Etxabe J \& Vazquez JA. Morbidity and mortality in Cushing's disease: an epidemiological approach. Clinical Endocrinology 1994 23 479-484.

12 Mancini T, Kola B, Mantero F, Boscaro M \& Arnaldi G. High cardiovascular risk in patients with Cushing's syndrome according to 1999 WHO/ISH guidelines. Clinical Endocrinology 200461 $768-777$.

13 Blau N, Miller WE, Miller ER Jr \& Cervi-Skinner SJ. Spontaneous remission of Cushing's syndrome in a patient with an adrenal adenoma. Journal of Clinical Endocrinology and Metabolism 197540 659-663.

14 Estopiñán V, Varela C, Riobo P, Dominguez JR \& Sancho J. Ectopic Cushing's syndrome with periodic hormonogenesis - a case suggesting a pathogenetic mechanism. Postgraduate Medical Journal $198763887-889$.

15 Newell-Price J, Bertagna X, Grossman AB \& Nieman LK. Cushing's syndrome. Lancet $2006 \mathbf{3 6 7} 1605-1617$.

16 Trainer PJ \& Besser GM. St Bartholomew's Hospital: The Bart's Endocrine Protocols. Edinburgh: Churchill-Livingstone, 1995.

17 Isidori AM, Kaltsas GA, Pozza C, Frajese V, Newell-Price J, Reznek RH, Jenkins PJ, Monson JP, Grossman AB \& Besser GM. The ectopic adrenocorticotropin syndrome: clinical features, diagnosis, management, and long-term follow-up. Journal of Clinical Endocrinology and Metabolism 200691 371-377.

18 Trainer PJ, Eastment C, Grossman AB, Wheeler MJ, Perry L \& Besser GM. The relationship between cortisol production rate and serial serum cortisol estimation in patients on medical therapy for Cushing's syndrome. Clinical Endocrinology 199339 441-443. 
19 Hellman L, Weitzman ED, Roffwarg H, Fukushima DK \& Yoshida K. Cortisol is secreted episodically in Cushing's syndrome. Journal of Clinical Endocrinology and Metabolism $19703 \mathbf{3 0}$ 686-689.

20 Krieger DT. Circadian pituitary adrenal rhythms. Advances in Experimental Medicine and Biology $1975 \mathbf{5 4} 169-189$.

21 Curtis GC. Long-term changes in corticosteroid excretion. In Biorhythms and Human Reproduction, pp 417-423. Eds M Ferin, F Halberg, RM Richart \& RL Vande Wiele, New York: John Wiley, 1974.

22 McCance DR, Gordon DS, Fannin TF, Hadden DR, Kennedy L, Sheridan B \& Atkinson AB. Assessment of endocrine function after transsphenoidal surgery for Cushing's disease. Clinical Endocrinology 199338 79-86.

23 Streeten DH, Anderson GH Jr, Dalakos T \& Joachimpillai AD. Intermittent hypercortisolism: a disorder strikingly prevalent after hypophysial surgical procedures. Endocrine Practice 19973 123-129.

24 Atkinson AB, Kennedy AL, Carson DJ, Hadden DR, Weaver JA \& Sheridan B. Five cases of cyclical Cushing's syndrome. BMJ 1985 291 1453-1457.

25 Shapiro MS \& Shenkman L. Variable hormonogenesis in Cushing's syndrome. Quarterly Journal of Medicine 199179 351-363.

26 Arnaldi G, Angeli A, Atkinson AB, Bertagna X, Cavagnini F, Chrousos GP, Fava GA, Findling JW, Gaillard RC, Grossman AB, Kola B, Lacroix A, Mancini T, Mantero F, Newell-Price J, Nieman LK, Sonino N, Vance ML, Giustina A \& Boscaro M. Diagnosis and complications of Cushing's syndrome: a consensus statement. Journal of Clinical Endocrinology and Metabolism 2003 88 5593-5602.

27 Hofmann BM, Hlavac M, Martinez R, Buchfelder M, Müller OA \& Fahlbusch R. Long-term results after microsurgery for Cushing disease: experience with 426 primary operations over 35 years. Journal of Neurosurgery $2008 \mathbf{1 0 8}$ 9-18.

28 Yasuda K \& Miura K. Unique type of Cushing's disease in clinical profile: cyclic Cushing's syndrome and Cushing's disease with favorable outcome to a high daily dose of bromocriptine. Nippon Naibunpi Gakkai Zasshi 199470 11-16.

29 Adachi M, Takayanagi R, Yanase T, Sakai Y, Ikuyama S, Nakagaki H, Osamura Y, Sanno N \& Nawata H. Cyclic Cushing's disease in long-term remission with a daily low dose of bromocriptine. Internal Medicine 199635 207-211.
30 Beckers A, Stevenaert A, Pirens G, Flandroy P, Sulon J \& Hennen G. Cyclical Cushing's disease and its successful control under sodium valproate. Journal of Endocrinological Investigation 199013 923-929.

31 Alexandraki KI \& Grossman AB. Pituitary-targeted medical therapy of Cushing's disease. Expert Opinion on Investigational Drugs 200817 669-677.

32 James VH, Landon J \& Wynn V. Oral and intravenous suppression tests in the diagnosis of Cushing's syndrome. Journal of Endocrinology 196533 515-524.

33 French FS, Macfie JA, Baggett B, Williams TF \& Van Wyk JJ. Cushing's syndrome with a paradoxical response to dexamethasone. American Journal of Medicine 196947 619-624.

34 Stratakis CA, Sarlis N, Kirschner LS, Carney JA, Doppman JL, Nieman LK, Chrousos GP \& Papanicolaou DA. Paradoxical response to dexamethasone in the diagnosis of primary pigmented nodular adrenocortical disease. Annals of Internal Medicine 1999131 585-591.

35 Yaneva M, Mosnier-Pudar H, Dugue MA, Grabar S, Fulla Y \& Bertagna X. Midnight salivary cortisol for the initial diagnosis of Cushing's syndrome of various causes. Journal of Clinical Endocrinology and Metabolism 200489 3345-3351.

36 Dahia PL \& Grossman AB. The molecular pathogenesis of corticotroph tumors. Endocrine Reviews $199920136-155$.

37 Jordan RM, Ramos-Gabatin A, Kendall JW, Gaudette D \& Walls RC. Dynamics of adrenocorticotropin (ACTH) secretion in cyclic Cushing's syndrome: evidence for more than one abnormal ACTH biorhythm. Journal of Clinical Endocrinology and Metabolism $198255531-537$.

38 Watanobe H, Aoki R, Takebe K, Nakazono M \& Kudo M. In vivo and in vitro studies in a patient with cyclical Cushing's disease showing some responsiveness to bromocriptine. Hormone Research 199136 227-234.

39 Scapagnini U, Van Loon R, Moberg GP, Preziosi P \& Ganong WF. Evidence for central norepinephrine-mediated inhibition of ACTH secretion in the rat. Neuroendocrinology 197210 155-160.

40 Hsu TH, Gann DS, Tsan KW \& Russell RP. Cyproheptadine in the control of Cushing's disease. Johns Hopkins Medical Journal 1981 $14977-83$.

Received 4 March 2009

Accepted 8 March 2009 